\title{
Prevalence, Factors Associated with Obesity and Overweight among Students in Brazzaville in 2020
}

\author{
Simplice Innocent Moussouami ${ }^{1,2 *}$, Issiako Bio Nigan', Yvon Rock Ghislain Alongo², \\ Polycarpe Gouthon ${ }^{1}$, François Mbemba ${ }^{2}$
}

\author{
${ }^{1}$ Sport, Health and Evaluation Research Unit (UR/SSE), National Institute for Youth, Physical Education and Sport (INJEPS), \\ University of Abomey-Calavi (UAC), Porto-Novo, Benin \\ ${ }^{2}$ Laboratory of Physiology of Effort and Biomechanics (LPB), Higher Institute of Physical Education and Sport (ISEPS), Marien \\ Ngouabi University, Brazzaville, Congo \\ Email: *simplicemoussouami@gmail.com
}

How to cite this paper: Moussouami, S.I., Nigan, I.B., Alongo, Y.R.G., Gouthon, P. and Mbemba, F. (2022) Prevalence, Factors Associated with Obesity and Overweight among Students in Brazzaville in 2020. Food and Nutrition Sciences, 13, 65-77.

https://doi.org/10.4236/fns.2022.131007

Received: August 9, 2021

Accepted: January 23, 2022

Published: January 26, 2022

Copyright $\odot 2022$ by author(s) and Scientific Research Publishing Inc. This work is licensed under the Creative Commons Attribution International License (CC BY 4.0).

http://creativecommons.org/licenses/by/4.0/

\begin{abstract}
Background: The prevalence of obesity is increasing dramatically around the world and it is reasonable to assume that young people attending school in Brazzaville are not spared. The objective of this study was to determine the prevalence, as well as the factors associated with obesity and overweight among students in Brazzaville. Methods: This is a cross-sectional study, conducted as a questionnaire survey with 2052 pupils ( 869 boys and 1183 girls, aged 14 to 18). Obesity and overweight were determined from the body mass index and reference curves of the International Obesity Task Force (IOTF), the associated factors, by performing the logistic regression. Results: The prevalence of overweight in private and public institutions was $15.6 \%$ versus $5.5 \%(\mathrm{p}<0.001)$ and obesity prevalence was $4.0 \%$ versus $1.5 \%(\mathrm{p}<0.001)$, respectively. The main factors associated with obesity and overweight were: parents' monthly income $(\mathrm{OR}=1.73)$, car as a means of transportation $(\mathrm{OR}=2.75)$ and family history of obesity ( $\mathrm{OR}=7.73$ ). On the other hand, attending a public school, walking and high levels of physical activity had a protective effect against obesity in this population. Conclusion: The prevalence of obesity was higher in private institutions and required management and prevention strategies.
\end{abstract}

\section{Keywords}

Adolescents, Secondary Schools, Weight Status, Risk Factors, Republic of Congo 


\section{Introduction}

Obesity is considered to be an excessive accumulation of body fat that can lead to adverse health consequences [1]. In addition to being a risk factor for cardiovascular disease, obesity is associated with a wide range of abnormalities such as hypertension, metabolic syndrome, certain cancers, sleep apnoea syndrome and type 2 diabetes [2] [3]. Obesity in children and adolescents presents risks that persist into adulthood. The shift from a diet rich in starchy, high-fibre to high fat animals, sugar and manufactured goods, and the reduction in physical activity associated with changes in social habits, are the main causes of obesity and overweight in young people [4].

Obesity is increasing rapidly, but this seemed to be the case only in developed countries. It is currently not sparing developing countries. It is now affecting children and adolescents, as indicated by the results of 450 national cross-sectional surveys in 144 countries, which report that 43 million children, i.e., a prevalence of $6.7 \%$, were considered overweight or obese in 2010 [5]. The same authors state that 35 million of these children are from developing countries and that this prevalence is expected to reach $9.1 \%$ by 2020 .

Several studies around the world have shown that obesity is increasingly prevalent in schools. For example, the overall prevalence of obesity and overweight among school children in Ghana was $16.4 \%$ [6]. In a study conducted with a sample of 1781 Tanzanian school children aged 12 - 18 years, $15.9 \%$ were overweight and $6.7 \%$ were obese [7]. High prevalence of adolescent obesity has been observed in Africa. In Algeria, it has been estimated at over 10\% for both sexes [8] and the Congo is not spared.

With the increase in the price of a barrel of oil in the period from 2001 to 2014, Brazzaville, the capital city, has modernized and experienced rapid demographic growth, due to a significant migratory flow. This phenomenon has been accompanied by an increase in the school enrolment rate, which rose from $73 \%$ in 1992 to $95 \%$ in 2017 [9]. As the improvement of school infrastructure, human and financial resources have not kept pace with this trend, a deterioration in the quality of education, which was almost exclusively public, has been observed over the same period. The democratization of the country's various sectors in 2001 led to the development of private education and a proliferation of public schools. These public schools are mainly attended by children from well-to-do families, who have adopted a new lifestyle characterized by car travel, consumption of high energy foods, sedentary lifestyle, etc. The consequences of this new lifestyle are not only a lack of education, but also a lack of knowledge about how to live and work. The consequences of this new lifestyle for adolescents need to be investigated.

Little work is available on the current situation of this population, particularly on the factors associated with obesity and overweight among Brazzaville students. To our knowledge, a study by Mbemba et al. [10] in a professional setting revealed that most people were underweight and had a low energy intake, as well as a risk 
of protein, magnesium, calcium and iron deficiency. Another school-based study in Brazzaville in 2007 of 862 pupils aged 7 - 18 years reported that overweight was $4.1 \%$ [11]. Similarly, in 2010, in the same locality and still in a school setting, an increase in the prevalence of overweight of $7.4 \%$ was observed in children and adolescents aged 7 to 16 years, all sexes combined [12].

Due to the rapid development of overweight in adolescents, the available data may be considered outdated and need to be updated. The aim of this study was therefore to determine the prevalence and risk factors associated with overweight and obesity among schoolchildren in Brazzaville in 2018.

\section{Material and Methods}

This is a cross-sectional study, carried out in 2020 in six high schools and colleges in Brazzaville, Republic of Congo. Initial meetings took place 72 hours before the actual survey with the heads of the schools, then with the students to discuss the objective and stages of the study, obtained their authorisation and agree on the date of the survey. On this occasion, a copy of the questionnaire and the informed consent form were given to each student interested in the study, with a view to informing their parents. The parents were asked to read both documents, sign the free and informed consent for their children's participation in the study, and then complete the socio-demographic section of the questionnaire. Both documents were collected the next day, after the completion check was carried out with the help of the schools' administration. The students were informed about the rest of the survey, which was to take place on the agreed day, after school, in a room that each school had made available to us. On the day of the survey, anthropometric measurements were taken and other data concerning the physical activity level of the students surveyed were recorded and transcribed on the questionnaire. The study was approved by the Comité Scientifique Sectoriel (CSS) des Sciences et Techniques des Activités Physiques et Sportives (STAPS) of the Université Marien Ngouabi de Brazzaville (Congo).

\subsection{Study Population and Sampling}

A sample of 2052 students (869 boys and 1183 girls aged between 14 and 18 years), well above the minimum number of 1623 students calculated from Schwartz's formula (1988), took part in the survey. Participants were selected using the random method and the three-level cluster technique. Thus, all volunteer pupils aged 14 to 18 years, attending classes of 4th, 3rd, 2nd and 1st year of six schools in the three geographical areas of Brazzaville drawn at random, were enrolled.

\subsection{Data Collection Tool and Procedures}

\subsubsection{Questionnaire}

A questionnaire was used to collect the first part of the socio-demographic data, i.e., sex, date of birth, body mass, height, waist circumference, area of residence of the pupil, means of transport used to go to school, occupation, monthly in- 
come and level of education of father. The second part of the questionnaire was the short version of the International Physical Activity Questionnaire (IPAQ), a validated tool used to determine Physical Activity Levels (PAL). The IPAQ consisted of six questions under four headings related to activities performed in the last seven days. These are: 1) intense activity; 2) moderate activity; 3) walking; and 4) sitting [13].

\subsubsection{Studied Variables}

The dependent variable in this study was weight status with two modalities: normo-weighted and overweight/obese. Any student with a BMI below the 85th percentile was considered normo-weighted and any student with a BMI above the 85th percentile was considered overweight/obese. The independent variables were: 1) the type of school which could be public or private; 2 ) the socio-economic status of the parents operationalised by the monthly income with three modalities: less than 250,000 CFA francs; 250,000 to 500,000 CFA francs; more than 500,000 CFA francs; 3 ) the educational level of the parents with three modalities: not enrolled, primary education level and secondary or higher education level; 4) the occupation of the parents with two modalities: office worker and manual worker; 5) means of travel with the three modalities bus/motorcycle, car, feet; 6) level of physical activity of students with the three modalities: low, moderate and high; and 7) sedentary time with three modalities: less than 2 hours/day, 2 to 4 hours/day, more than 4 hours/day.

\subsubsection{Procedures}

On the day of the survey, the pupils present were received in groups of twenty, by each of two trained assistant researchers. The measurements were carried out by the trained researchers using the same standard tools and the data were transcribed onto the first part of the questionnaire which was then returned to them. The other parts of the questionnaire (dietary habits, level of physical activity) were then filled in by each student under the supervision of the assistant investigators who provided explanations if necessary.

\subsubsection{Anthropometric Measurements and Body Composition}

Body mass and height were measured to the nearest $0.1 \mathrm{~kg}$ and $0.1 \mathrm{~cm}$ respectively, using a BC535 multifunctional impedance meter scale (Tanita, Japan) which also determined the percentage of fat and a Seca 216 wall-mounted stadiometer (Seca SA, Semur-en-Auxois, France). Body mass index was calculated using the formula $\mathrm{BMI} /$ height $^{2}\left(\mathrm{~kg} / \mathrm{m}^{2}\right)$. Waist circumference was measured with an accuracy of 0.1 $\mathrm{cm}$, using a flexible, non-stretchable tape measure with a spring to regulate the tension applied during measurement. Weight status was defined using the IOTF (International Obesity Task Force) BMI cut-off points for age and gender [14].

\subsubsection{Physical Activity Level}

Activity level was measured using the International Physical Activity Question- 
naire (IPAQ). Three levels of physical activity are defined by the IPAQ group: high (>MET-min/week), moderate (600 to $1500 \mathrm{MET}-\mathrm{min} /$ week) and low (less than 600 MET-min/week). The averages obtained were used to determine three levels of sedentary behaviour: $<2 \mathrm{~h}, 2$ to $4 \mathrm{~h}$ and $>4 \mathrm{~h}$ per day.

\subsection{Statistical Analysis}

Data were entered into Epi Info and processed with SPSS Inc. software (version 22.0, USA). Differences in prevalences and anthropometric data were determined using the chi-square test and Student's t-test for independent samples, respectively. Logistic regression analysis with calculation of the odds ratio (OR) was performed to determine the association between socioeconomic characteristics, physical activity level (independent variables) and overweight and obesity (dependent variable). A univariate analysis was first performed to identify the independent variables significantly associated with overweight and obesity. These variables were then entered into the multivariate logistic regression analysis to determine the strongest associations with the dependent variable. The significance level of the statistical tests was set at $\mathrm{p}<0.05$.

\section{Results}

The mean age of the students studied was $15.00 \pm 1.19$ years with a mean weight of $54.99 \pm 10.48 \mathrm{~kg}$ (Table 1$)$.

Females accounted for $57.7 \%$ of the sample. The percentage of students with a family history of obesity was $8.5 \%$, the percentage of students who came to school by car was $20.7 \%$, and students from parents with secondary or higher education represented $93.0 \%$ of the sample studied. The number of pupils from public and public schools was $1022(49.8 \%)$ and 1030 (50.2\%) respectively. The total prevalence of overweight and obesity among the pupils surveyed (Table 2) was $3.5 \%$ and $9.8 \%$ respectively. This prevalence was higher in private than in

Table 1. Anthropometric characteristics of school adolescents in Brazzaville $(n=2052)$.

\begin{tabular}{ccccc}
\hline & \multicolumn{2}{c}{ Private schools $(\mathrm{n}=1030)$} & \multicolumn{2}{c}{ Public schools $(\mathrm{n}=1022)$} \\
\cline { 2 - 5 } & Boys & Gils & Boys & Gils \\
\hline Age (years) & $15.5 \pm 1.3^{* *}$ & $15.2 \pm 1.26$ & $15.3 \pm 1.1^{* * *}$ & $15.1 \pm 1.0$ \\
Height (m) & $1.63 \pm 0.07^{* * *}$ & $1.61 \pm 0.06$ & $1.63 \pm 0.08$ & $1.60 \pm 0.06$ \\
Weight (kg) & $57.0 \pm 10.9$ & $57.0 \pm 12.4$ & $52.8 \pm 7.9$ & $51.7 \pm 8.0$ \\
BMI (kg/m $)$ & $21.5 \pm 3.9$ & $22.1 \pm 4.3^{*}$ & $20.1 \pm 3.0$ & $20.2 \pm 2.9$ \\
\%G & $18.8 \pm 4.5$ & $24.6 \pm 7.9$ & $17.5 \pm 3.9$ & $23.1 \pm 6.6^{* * *}$ \\
TT $(\mathrm{cm})$ & $78.4 \pm 9.4^{* * *}$ & $75.7 \pm 9.1$ & $76.5 \pm 7.6^{* * *}$ & $73.1 \pm 6.7$ \\
\hline
\end{tabular}

BMI: body mass index; \%F: percentage of fat; WC: waist circumference; Numbers in the table refer to means \pm standard deviation; ${ }^{*}$ : difference between girls and boys significant at $\mathrm{p}<0.05{ }^{* *}$ : difference between girls and boys significant at $\mathrm{p}<0.01$; ${ }^{* *}$ : difference between girls and boys significant at $\mathrm{p}<0.001$. 
Table 2. Frequency distribution of weight status among school adolescents in Brazzaville $(\mathrm{n}=2052)$.

\begin{tabular}{|c|c|c|c|c|c|c|}
\hline & \multicolumn{2}{|c|}{ Private schools $(\mathrm{n}=1030)$} & \multirow{2}{*}{$\begin{array}{l}\text { Total \% } \\
\text { [IC 95\%] }\end{array}$} & \multicolumn{2}{|c|}{ Public schools $(n=1022)$} & \multirow{2}{*}{$\begin{array}{c}\text { Total \% } \\
\text { [IC à 95\%] }\end{array}$} \\
\hline & $\begin{array}{c}\text { Boys \% } \\
\text { [IC 95\%] }\end{array}$ & $\begin{array}{c}\text { Gils \% } \\
\text { [IC 95\%] }\end{array}$ & & $\begin{array}{c}\text { Boys } \\
\%[\text { IC 95\%] }\end{array}$ & $\begin{array}{c}\text { Gils \% } \\
\text { [IC 95\%] }\end{array}$ & \\
\hline Maigres & $19.1[15.3-22.8]$ & $17.9[16.0-20.8]$ & $18.4[21.1-29.2]$ & $25.1[21.1-29.2]$ & $23.0[19.6-26.4]$ & $23.9[21.3-26.5]$ \\
\hline Normo pondérés & $60.1[55.4-64.8]$ & $60.5[56.6-64.4]$ & $60.3[57.4-63.3]$ & $69.6[65.3-73.9]$ & $71.2[67.5-74.9]$ & $70.5[67.7-73.3]$ \\
\hline Surpoids & $14.5[11.7-17.3]$ & $17.2[13.6-20.8]$ & $15.6[13.4-17.8]$ & $3.6[1.8-5.3]$ & $4.33[2.6-5.9]$ & $4.0[2.8-5.2]$ \\
\hline Obèses & $3.5[1.7-5.3]$ & $6.9[4.9-8.9]$ & $5.5[4.1-6.9]$ & $1.4[0,4-2.30]$ & $1.5[0,4-2.7]$ & $1.5[0.7-2.2]$ \\
\hline
\end{tabular}

CI: 95\% confidence interval; n: number of people.

public schools (15.6\% [95\% CI: 13.4 - 17.8] versus 4.0\% [95\% CI: $2.8-5.2$ ] and 5.5\% [95\% CI: 4.1 - 8.9] versus 1.5\% [95\% CI: 0.7 - 2.2] ( $<<0.001)$. The prevalence of obesity among girls in public schools was 6.9\% [95\% CI: 4.9 - 8.9] higher than that of boys 3.5\% [95\% CI: $1.7 \%-5.3 \%$ ]. The same was true for the prevalence of overweight among girls 17.2\% [CI 95\%: 13.6\% - 20.8\%] versus $14.5 \%$ [CI 95\%: $11.7 \%$ - 17.3\%]. Among the 1022 participants from public schools, the prevalence of obesity among boys and girls was $1.4 \%$ [CI 95\%: $0.4 \%-2.30 \%$ ] and 1.5\% [CI 95\%: 0.4\% - 2.7\%], respectively, and the prevalence of overweight was 3.6\% [CI 95\%: 1.8\% - 5.3\%] and 4.33\% [CI 95\%: 2.6\% - 5.9\%], respectively.

The regression analysis showed that obesity was inversely associated with the type of institution $(\mathrm{OR}=0.22)$. On the other hand, obesity was significantly associated with the use of the car as a means of transport ( $O R=2.75)$, with the monthly income of the parents $(\mathrm{OR}=1.73)$ in the case of children in public schools. The level of sedentary behaviour (less than 4 hours per day) in both private ( $O R=$ 12.60 ) and public schools ( $O R=2.60$ ) was also significantly associated with obesity. Finally, family history of obesity had a significant contribution (OR $=4.43$ in private versus 7.70 in public) (Table 3 ).

\section{Discussion}

The objectives of this study were to investigate the prevalence of overweight and obesity and to identify associated factors in the population of adolescents aged 14 - 18 years in secondary schools in Brazzaville, Congo.

\subsection{Validity and Reliability}

The sample of students enrolled in this study was drawn using the random method and the three-stage stratified cluster technique. The actual sample size was much larger than the theoretical sample size calculated from the Schwartz (1988) formula. In order to ensure the reliability of the data collected, a validated questionnaire and electronic equipment were used to carry out the various measurements. Robust tests were used for the statistical analysis of the data. These various precautions suggest that the results obtained can be generalized to the entire population of obese adolescents attending school in Brazzaville. However, some 
Table 3. Univariate and multivariate models of socioeconomic factors and level of physical activity associated with overweight and obesity among school adolescents in Brazzaville $(\mathrm{n}=2052)$.

\begin{tabular}{|c|c|c|c|c|c|c|c|c|}
\hline & \multicolumn{4}{|c|}{ Private schools $(\mathrm{n}=1030)$} & \multicolumn{4}{|c|}{ Public schools $(n=1022)$} \\
\hline & $\begin{array}{c}\text { Not } \\
\text { obese } \\
(\mathrm{n}=812)\end{array}$ & $\begin{array}{c}\text { Obese } \\
(n=218)\end{array}$ & $\begin{array}{l}\text { OR brut } \\
\text { (IC 95\%) }\end{array}$ & $\begin{array}{l}\text { Adjusted OR } \\
\text { (IC 95\%) }\end{array}$ & $\begin{array}{c}\text { Not } \\
\text { obese } \\
(n=966)\end{array}$ & $\begin{array}{c}\text { Obese } \\
(\mathrm{n}=56)\end{array}$ & $\begin{array}{l}\text { Crude OR } \\
\text { (IC 95\%) }\end{array}$ & $\begin{array}{l}\text { Adjusted OR } \\
\text { (IC à 95\%) }\end{array}$ \\
\hline $\begin{array}{l}\text { Means } \\
\text { of travel }\end{array}$ & & & & & & & & \\
\hline - Bus/motorcycle & 187 & 141 & 1.00 & 1.00 & 89 & 8 & 1.00 & 1.00 \\
\hline - Car & 126 & 32 & $\begin{array}{c}2.36 \\
(1.5-3.8)^{\star \star \star}\end{array}$ & $\begin{array}{c}2.75 \\
(1.75-4.42)^{\star \star \star}\end{array}$ & 197 & 17 & $\begin{array}{c}0.88 \\
(0.33-2.16)\end{array}$ & $\begin{array}{c}0.88 \\
(0.33-2.16)\end{array}$ \\
\hline - Foot & 489 & 45 & $\begin{array}{c}0.33 \\
(0.19-0.50)^{\star * *}\end{array}$ & $\begin{array}{c}0.36 \\
(0.22-0.59)^{\star \star \star}\end{array}$ & 680 & 31 & $\begin{array}{c}0.54 \\
(0.29-1.03)^{\star \star \star}\end{array}$ & $\begin{array}{c}0.54 \\
(0.29-1.03)^{\star \star \star}\end{array}$ \\
\hline \multicolumn{9}{|l|}{$\begin{array}{c}\text { Parents } \\
\text { occupation }\end{array}$} \\
\hline - Unemployed & 36 & 8 & 1.00 & 1.00 & 68 & 1,00 & 1.00 & 1.00 \\
\hline - Office worker & 627 & 189 & $\begin{array}{c}0.73 \\
(0.30-1.85)\end{array}$ & $\begin{array}{c}0.79 \\
(0.36-1.31)\end{array}$ & 376 & 28 & $\begin{array}{c}3.88 \\
(0.77-70.51)\end{array}$ & $\begin{array}{c}3.88 \\
(0.77-70.51)\end{array}$ \\
\hline - Manual worker & 149 & 21 & $\begin{array}{c}0.46 \\
(0.15-1.85)\end{array}$ & $\begin{array}{c}0.49 \\
(0.16-1.91)\end{array}$ & 522 & 27 & $\begin{array}{c}3.07 \\
(0.63-55.57)\end{array}$ & $\begin{array}{c}3.07 \\
(0.63-55.57)\end{array}$ \\
\hline \multicolumn{9}{|l|}{$\begin{array}{c}\text { Monthly } \\
\text { income }\end{array}$} \\
\hline $\begin{array}{l}\text { - From } 200,000 \\
\text { to } 500,000\end{array}$ & 485 & 119 & 1.00 & 1.00 & 83 & 6 & 1.00 & 1.00 \\
\hline - Less than 200,000 & 142 & 16 & $\begin{array}{c}1.32 \\
(0.71-2.20)\end{array}$ & $\begin{array}{c}1.51 \\
(0.81-2.51)\end{array}$ & 304 & 11 & $\begin{array}{c}1.38 \\
(0.69-2.95)\end{array}$ & $\begin{array}{c}1.38 \\
(0.69-2.95)\end{array}$ \\
\hline - More than 500,000 & 185 & 83 & $\begin{array}{c}1.64 \\
(0.84-3.71)^{\star *}\end{array}$ & $\begin{array}{c}1.73 \\
(0.50-1.78)^{\star *}\end{array}$ & 579 & 39 & $\begin{array}{c}1.25 \\
(0.38-3.76)\end{array}$ & $\begin{array}{c}1.25 \\
(0.38-3.76)\end{array}$ \\
\hline \multicolumn{9}{|l|}{$\begin{array}{l}\text { Family } \\
\text { history of } \\
\text { obesity }\end{array}$} \\
\hline - No & 736 & 154 & 1.00 & 1.00 & 959 & 31 & 1.00 & 1.00 \\
\hline - Yes & 76 & 64 & $\begin{array}{c}4.38 \\
(2.98-6.45)^{\star * *}\end{array}$ & $\begin{array}{c}4.43 \\
(3.08-6.71)^{\star * \star}\end{array}$ & 10 & 25 & $\begin{array}{c}7.54 \\
(3.42-17.98)^{\star \star \star}\end{array}$ & $\begin{array}{c}7.70 \\
(3.50-18.11)^{\star \star \star}\end{array}$ \\
\hline \multicolumn{9}{|l|}{$\begin{array}{c}\text { Physical } \\
\text { ability level }\end{array}$} \\
\hline - Low & 28 & 115 & 1.00 & 1.00 & 41 & 33 & 1.00 & 1.00 \\
\hline - Moderate & 434 & 89 & $\begin{array}{c}0.04 \\
(0.02-0.08)^{\star * *}\end{array}$ & $\begin{array}{c}0.02 \\
(0.02-0.08)^{\star * *}\end{array}$ & 265 & 19 & $\begin{array}{c}0.03 \\
(0.0-0.07)^{\star * *}\end{array}$ & $\begin{array}{c}0.05 \\
(0.0-0.08)^{\star \star \star}\end{array}$ \\
\hline - High & 350 & 14 & $\begin{array}{c}0.01 \\
(0.01-0.02)^{\star * *}\end{array}$ & $\begin{array}{c}0.07 \\
(0.01-0.12)^{\star * *}\end{array}$ & 660 & 4 & $\begin{array}{c}0.01 \\
(0.00-0.03)^{* * *}\end{array}$ & $\begin{array}{c}0.02 \\
(0.00-0.04)^{\star * *}\end{array}$ \\
\hline \multicolumn{2}{|l|}{ Sedentary } & & & & & & & \\
\hline - $[2,4]$ hours/day & 634 & 63 & 1.00 & 1.00 & 801 & 29 & 1.00 & 1.00 \\
\hline
\end{tabular}




\section{Continued}

\begin{tabular}{lcccccccc}
\hline$-<$ hours/day & 39 & 0 & 0.08 & 0.04 & 56 & 0 & 0.004 & 0.004 \\
& & & $(0.05-0.27)$ & $(0.00-1.43)$ & & & $(0.00-1.42)$ & $(0.00-0.46)$ \\
$->4$ hours/day & 139 & 155 & 11.5 & 12.6 & & & 1.21 & 2.60 \\
& & & $(7.5-18.0)^{* * *}$ & $(5.61-28.63)^{* * *}$ & 109 & 27 & $(0.57-2.83)^{* * *}$ & $(0.62-2.91)^{* * *}$ \\
\hline
\end{tabular}

OR: odds ratio; $95 \%$ CI: 95\% confidence interval; n: number of participants; ${ }^{*}$ : OR significant at $\mathrm{p}<0.05 ;{ }^{* *}$ : OR significant at $\mathrm{p}<$ $0.01^{* * *}$ : OR significant at $\mathrm{p}<0.001$.

limitations should be noted. The first is due to the type of study and its crosssectional nature, which only allows a temporal snapshot of the phenomenon studied. The second stems from the information collected on morbid antecedents and lifestyle, which was based solely on the participants' declarations, without any other rigorous verification. Finally, as regards the measurement of economic status, there is no standardized grid, which may explain the heterogeneity of the results of the work on adolescents. These various limitations do not, however, affect the observations of this study, whose results can be considered valid, reliable and therefore generalizable to all pupils in the city of Brazzaville.

\subsection{Prevalence of Overweight and Obesity}

The low prevalence of overweight and obesity recorded in this study seems surprising. Given the trend in the evolution of this disease, the context (urban environment) and the target population studied (adolescents attending school in the capital of Congo), it was reasonable to expect higher values than those reported in 2012 [12]. However, two arguments could justify these results. The first is related to the reference standards used for the classification of obesity. The IOTF reference curves used in this study to determine weight status may have introduced differences from the WHO references in the other studies. The other argument relates to the nature of the target population studied. In this study it was exclusively adolescents aged $14-18$ years, whereas the other studies involved a more heterogeneous population, including other age groups in addition to adolescents.

The prevalence rates of overweight and obesity among school-going adolescents in Brazzaville obtained in this study are similar to those found among Togolese adolescents aged 8 - 14 years, in whom overweight was 5\% and obesity $13.7 \%$ [15]. On the other hand, they are higher than the rates of $8.8 \%$ overweight and 3.1\% obesity recorded among Ethiopian pupils in Bahir Da [16]. Our results are also higher than those of a previous study conducted in the Democratic Republic of Congo among adolescents, which reported prevalence rates of overweight and obesity of $10 \%$ versus $1.5 \%$ among girls and $5 \%$ versus $0.4 \%$ among boys [4]. They are also higher than the rates of $0 \%$ obesity and 5\% [IC 95\%: 1.0\% - 8.8\%] overweight reported in Ouidah in Benin [17].

These high prevalences of overweight and obesity observed in our sample may be due to the current lifestyle of Brazzavillians, characterized by a reduction in 
physical activity to the detriment of motorized means of transport and an increase in the consumption of foods rich in fat and sugar. Differences in prevalence were found between girls and boys, with a predominance of girls in both types of institution.

The significantly higher rates of obesity and overweight among girls can be attributed to the low levels of physical activity that girls tend to engage in, as they also have little leisure time. The low physical activity of girls is generally associated with the frequency of travelling to school by means of transport (bus and car). One plausible explanation is related to the role assigned to girls and boys by African culture. Thus, intense physical exercise is considered more appropriate for boys. In contrast, housework and other low-intensity physical activities are reserved exclusively for girls.

The study also found a higher prevalence of overweight and obesity among adolescents attending private schools. However, these results are lower than those obtained in South Africa in public schools, which reported $8.57 \%$ obesity and $15.43 \%$ overweight [18]. These results were also observed in a study conducted in Lithuania among students, which estimated the prevalence of obesity among boys and girls at $11.7 \%$ and $12.6 \%$ and $4.9 \%$ and $3.4 \%$ respectively [19]. This trend is thought to be due to the fact that adolescents in public schools are predominantly from families with a high socio-economic level (monthly income). This status of the parents gives them the possibility to consume luxury foods that are often energetic (fast food, schawarmas, cakes, etc.) purchased in shops. Also, the ability of these social groups to obtain imported food is perceived in the Congolese environment as a positive enhancement and a sign of good health. These observations also reflect the lack of health education and poor lifestyle habits (no extracurricular sports, snacking) among these pupils. In this context, we note that public school children from privileged backgrounds have less physical activity (home-schoolhome travel by vehicle) and they spend a lot of time in front of television screens, doing less and less domestic activities.

\subsection{Factors Associated with Overweight}

The risk of becoming overweight and obese was 44 times higher in pupils attending public schools and from parents with a high socio-economic status. Socioeconomic status is one of the important factors to be considered for its strong association with weight gain. Numerous studies in middle-income countries have shown this significant relationship between obesity and children who travel by car at least some of the time and who come from parents with high income and education. Our results are in line with those of authors who found that higher socio-economic status increased the risk of obesity [20]. These other authors found that parents' monthly income, father's education level higher than high school were all significant predictors of overweight and obesity [20]. In contrast, other authors found that Saudi adolescents were likely to be obese while all parental socioeconomic variables were not significantly associated with obesity [21]. 
Another finding of this study suggests that low physical activity level is significantly associated with weight gain. These observations are consistent with those of a study predicting obesity in adolescents $(\mathrm{OR}=2.29 ; 95 \% \mathrm{CI}=1.45-3.68)$ [6]. The same finding was made in Benin in a study that found that low physical activity (OR $=44.93$; 95\% CI: 35.06 - 57.58) was a predictor of overweight [17]. Finally, a study in Ghana with 543 children aged 8 - 17 years found that a sedentary lifestyle characterized by time spent watching television, computers and video games was a risk factor [6].

Our results contrast with those of a study that showed that physical activity level was not associated with the occurrence of obesity in adolescents [22]. The same results were found in Palestinian adolescents [23]. These data obtained attest to the fact that the obese adolescents in this study do not participate in extracurricular physical activity in the physical education and sports classes organized in their schools. The main reason given for this was that they had more body fat than the normal weight group.

The parents' pathological history is an important contributor to weight gain in adolescents. These results corroborate those of a previous study that showed that parental body weight influences children's weight gain [24]. Similarly, epidemiological studies estimate the role of heredity in the development of early obesity at between $30 \%$ and 50\%. According to these studies, a child is eight times more likely to become obese when both parents are already obese, compared to a child with parents of normal weight. Finally, compared to their normo-weighted counterparts, overweight adolescents in Brazzaville very generally have obese parents. The reasons are both behavioural and genetic. $70 \%$ of obese children have an obese parent. If one parent is massively obese, the risk in the offspring is multiplied by 5 [24].

\section{Conclusion}

The objectives of this study were: 1) to estimate the prevalence of obesity and overweight in private and public schools in Brazzaville; 2) to determine the factors associated with obesity and overweight in this population. The results show that the prevalence of overweight and obesity among adolescents attending school in the city of Brazzaville is higher in public schools than in public schools. They also show that the type of school, the socio-economic status of the parents and the level of physical activity are factors associated with obesity in this population. These results merit special attention and, consequently, the implementation of a strategy to prevent and combat this scourge. As a precaution, a programme that includes nutritional education and some forms of physical exercise for these adolescents could help to curb this problem. However, in the short- and mediumterm, awareness campaigns on obesity and its consequences should be considered. At the level of these schools, programmes should be set up that are more adapted to all pupils, including obese children, in order to better interest them in physical activities and sports. 


\section{Acknowledgements}

This research was financed by our own funds. We would like to thank the students from various schools in Brazzaville who participated in the collection of data for this study.

State of knowledge on the subject:

- The prevalence of obesity is increasing in a worrying way in the southern countries;

- Lifestyle change and dietary transition are the main factors associated with the increase in obesity.

\section{Contributions of the Study to Knowledge}

- The study showed that the prevalence of obesity is higher in public schools than in public schools in the capital city of Congo (Brazzaville);

- It also revealed that the type of school, the socio-economic status of parents and the level of physical activity were factors associated with obesity;

- She suggested that parents and governments on our continent should be aware of the rapid evolution of this phenomenon in order to take appropriate precautions based on the identified associated factors.

\section{Conflicts of Interest}

The authors declare no conflict of interest.

\section{Contribution of the Authors}

All authors have read and approved the final manuscript.

\section{References}

[1] World Health Organization (2016) Obesity and Overweight. Fact Sheet. 311.

[2] Ormazabal, V., Nair, S., Elfeky, O., Aguayo, C., Salomon, C. and Zuñiga, F.A. (2018) Association between Insulin Resistance and the Development of Cardiovascular Disease. Cardiovascular Diabetology, 17, Article No. 122. https://doi.org/10.1186/s12933-018-0762-4

[3] Regaieg, S., Charfi Elleuch, M., Mnif, F., Marrakchi, R. and Yaich, S. (2015) Obesity Physical Activity and Sedentary Time in School-Going Adolescents, Aged 15-18 Years in the City of Sfax (Tunisia). The Pan African Medical Journal, 22, 370-376. https://doi.org/10.11604/pamj.2015.22.370.6121

[4] Musungi, J.M., Muyumba, E.K., Nkulu, D.N., Kakoma, P.K., Mukuku, O., Kamalo, B.K.M., et al. (2019) Prevalence of Adolescent Overweight and Obesity in School Settings in Lumumbashi, Democratic Republic of Congo. The Pan African Medical Journal, 32, Article No. 49. https://doi.org/10.11604/pamj.2019.32.49.15969

[5] De Onis, M., Onyango, A.W., Van den Broeck, J., Chumlea, W.M.C. and Martorell, R. (2004) Protocols for Measurement and Standardisation of Anthropometry Used in the Construction of a New International Growth Reference. Food and Nutrition Bulletin, 25, S27-S36. https://doi.org/10.1177/15648265040251S105

[6] Adom, T., De Villiers, A., Puoane, T. and Kengne, A.P. (2019) Prevalence and Correlates of Overweight and Obesity among School Children in an Urban District of 
Ghana. BMC Obesity, 6, Article No. 14. https://doi.org/10.1186/s40608-019-0234-8

[7] Pangani, I.N., Kiplamai, F.K., Kamau, J.W. and Onywera, V.O. (2016) Prevalence of Overweight and Obesity among Primary School Children Aged 8-13 Years in Dar es Salaam City, Tanzania. Advances in Preventive Medicine, 2016, Article ID: 1345017. https://doi.org/10.1155/2016/1345017

[8] Fedala, N., Mekimene, L., Haddam, A.E.M. and Fedala, N.S. (2015) Association between Body Mass Index, Physical Activity and Sedentary Lifestyle in Algerian Adolescents. International Journal of Innovation and Applied Studies, 10, 489-497.

[9] Model Equine Photo Showers Association (2018) Directorate of Studies and School Planning (DEPS), Statistical Ring Finger 2016-2017. Brazzaville.

[10] Mbemba, F., Ouissika, S.G. and Senga, P. (2007) Carbohydrate Intake in the Diet of High-Level Athletes in Brazzaville: Repercussions on Dietary Balance. Medicine Nutrition, 43, 80-87. https://doi.org/10.1051/mnut/2007432080

[11] Mabiala-Babela, J.R., Alima, J.S., Monabeka, H.G., Cardorelle, A.M., Nkoua, J.L. and Moyen, G. (2011) Epidemiological and Clinical Profile of Childhood Obesity in Brazzaville (Congo). Cahiers de Nutrition et de Diététique, 46, 259-262. https://doi.org/10.1016/j.cnd.2011.09.002

[12] Mabiala-Babela, J.R., Sabbaye, G., Monabeka, H.G. and Moyen, G. (2012) Obesity in Congolese Adolescents in the School Setting: Epidemiological and Clinical Aspects. Cahiers de Nutrition et de Diététique, 13, 1082-1085.

[13] Pereira, M.A., Fitzergerald, S.J., Gregg, E.W., et al. (1997) A Collection of Physical Activity Questionnaires for Health-Related Research. Medicine \& Science in Sports \& Exercise, 29, S1-S205.

[14] Cole, T.J. (2000) Establishing a Standard Definition for Child Overweight and Obesity Worldwide: International Survey. British Medical Journal, 320, 1240-1242. https://doi.org/10.1136/bmj.320.7244.1240

[15] Sagbo, H., Ekouevi, D.K., Ranjandriarison, D.T., Niangoran, S., Bakai, T.A., Afanvi, A., et al. (2018) Prevalence and Factors Associated with Overweight and Obesity among Primary School Children in Urban Areas of Lomé, Togo. Public Health $\mathrm{Nu}$ trition, 21, 1048-1056. https://doi.org/10.1017/S1368980017003664

[16] Mekonnen, T., Tiriku, A. and Abebe, S.M. (2018) Overweight/Obesity among School Children in Bahir Dar: A Cross-Sectional Study. Italian Journal of Pediatrics, 44, 21-23. https://doi.org/10.1186/s13052-018-0452-6

[17] Makoutode, A., Saizounou, J., Ahanhanzo, Y.G., Sossa, C.J. and Agueh, V. (2017) Prevalence and Factors Associated with Overweight among Adolescents in a Secondary City in Benin. International Journal of Biological and Chemical Sciences, 11, 798-803. https://doi.org/10.4314/ijbcs.v11i2.21

[18] Ngwenya, N.A. and Ramukumba, T.S. (2017) Prevalence of Obesity among High School Adolescents in Tsawane Town. Curat, 40, a1662. https://doi.org/10.4102/curationis.v40i1.1662

[19] Smetanina, N., Albaviciute, E., Babinska, V., Karinauskiene, L., Albertsson-Wikland, K., Petrauskiene, A., et al. (2015) Prevalence of Overweight/Obesity in Relation to Dietary and Lifestyle Habits among Children and Adolescents Aged 7-17 Years in Lithuania. BMC Public Health, 15, 1001-1005. https://doi.org/10.1186/s12889-015-2340-y

[20] Adetunji, A.E., Adeniran, K.A., Olomu, S.C., Odike, A.I., Ewah-Odiase, R.O., Omoike, I.U., et al. (2019) Socio-Demographic Factors Associated with Overweight and Obesity among Primary School Children in Semi-Urban Areas of West Central Nigeria. PLoS ONE, 14, e0214570. https://doi.org/10.1371/journal.pone.0214570 
[21] Mahfouz, A.A., Shatoor, A.S., Khan, M.Y., Daffalla, A.A., Mostafa, O.A. and Hassanein, M.A. (2011) Nutrition, Physical Activity and Gender-Related Risks for Adolescent Obesity in Southwestern Saudi Arabia. Saudi Journal of Gastroenterology, 17, 318-322. https://doi.org/10.4103/1319-3767.84486

[22] Zakrzewski, J.K., Gillison, F.B., Cumming, S., Church, T.S., Katzmarzyk, P.T., Broyles, S.T., et al. (2015) Associations between Breakfast Frequency and Adiposity Indicators in Children from 12 Countries. International Journal of Obesity Supplements, 5 , S80-S88. https://doi.org/10.1038/ijosup.2015.24

[23] Kelsy, M.M., Zaepfel, A., Bjornstad, P. and Nadeau, K.J. (2014) Age-Related Consequences of Childhood Obesity. Geront, 60, 222-228.

https://doi.org/10.1159/000356023

[24] Martínez-Villanueva, J., González-Leal, R., Argente, J. and Martos-Moreno, G.Á. (2019) Parental Obesity Is Associated with the Severity of Childhood Obesity and Its Comorbidities. Anales de Pediatría, 90, 224-231.

https://doi.org/10.1016/j.anpedi.2018.06.013 